\title{
Return to play after conservative treatment in athletes with symptomatic lumbar disc herniation: a practice-based observational study
}

This article was published in the following Dove Press journal:

Open Access Journal of Sports Medicine

I7 March 201।

Number of times this article has been viewed

\author{
Jun Iwamoto' \\ Yoshihiro Sato ${ }^{2}$ \\ Tsuyoshi Takeda' \\ Hideo Matsumoto' \\ 'Institute for Integrated Sports \\ Medicine, Keio University School of \\ Medicine, Tokyo, Japan; ${ }^{2}$ Department \\ of Neurology, Mitate Hospital, \\ Fukuoka, Japan
}

\begin{abstract}
The purpose of the study was to confirm the short-term outcome of conservative treatment in terms of the ability to return to play and factors influencing return to play in athletes with symptomatic lumbar disc herniation. A total of 100 consecutive athletes (72 male and 28 female) who consulted our sports medicine clinic during the 16-year period between September 1993 and October 2009 because of severe low back pain and/or leg pain/numbness due to lumbar disc herniation were studied. The mean age of the subjects was 23 years. All of them were conservatively treated by being advised to discontinue their sporting activities with/without short-term medication. After the subjective symptoms had reduced by more than $80 \%$, individual training was started in order to allow the athletes to return to play. Seventy-nine athletes $(79.0 \%)$ returned to play at an average of 4.8 months (range 1-12 months) after the start of treatment and were able to sustain the activities for at least 6 months, the minimum duration of follow-up in the study. The outcome of the conservative treatment was not influenced by the intensity of the sporting activity. Multiple logistic regression analyses showed that the severity of the symptoms prior to the start of treatment was the factor influencing the ability of the athletes to return to play. The present study confirmed the satisfactory short-term outcome of conservative treatment in athletes with symptomatic lumbar disc herniation regarding return to play and revealed that subjective symptoms prior to the start of treatment appeared to be a key factor in return to play after conservative treatment.
\end{abstract}

Keywords: lumbar disc herniation, athletes, return to play, conservative treatment, sciatica, low back pain

\section{Background}

Lumbar spine injuries such as lumbar disc herniation, spondylolysis, spondylolisthesis, and various types of fracture are not uncommon in athletes. ${ }^{1,2}$ Lumbar disc herniation is a common condition causing back pain and/or leg pain/numbness. Management of lumbar disc herniation is a challenge in athletes, because it often prevents them from continuing their sporting activities. It is important to keep in mind that the goal of treatment in athletes is to allow them to return to play as early as possible.

Conservative treatment or surgeries, including conventional open discectomy, microdiscectomy, percutaneous laser discectomy, percutaneous discectomy, and microendoscopic discectomy (MED), are available for athletes and nonathletes with lumbar disc herniation. ${ }^{3}$ However, there is no agreement on the optimal strategy for the management of lumbar disc herniation in athletes, because no randomized controlled trials of conservative versus various surgical treatment methods in athletes with symptomatic lumbar disc herniation have been reported. Unless athletes with 
lumbar disc herniation have cauda equine syndrome and progressive neurological deficit, ${ }^{2}$ conservative treatment by way of discontinuation of the aggravating sports activity may play a primary role in reducing the severity of the symptoms. The following two points should be borne in mind, ${ }^{4}$ especially in athletes: i) surgery must be avoided in patients with a herniated disc who may become asymptomatic, or even have reversal of the disc herniation, within a few months after the onset of symptoms; and ii) protracted conservative treatment that may lengthen the time off from sports activities and reduce the chance of successful surgical treatment must be avoided. It is debatable which method should be chosen, conservative or surgical treatment, from the point of view that athletes should be treated with the goal of allowing them to return as early as possible to active participation in sports activities. Continued pain and inability to compete in athletic competition may be the relative indications of surgical treatment. ${ }^{2}$

A review of the literature regarding the efficacy of conservative or surgical treatment in athletes with lumbar disc herniation revealed that the percentages of athletes who returned to play were $78.9 \%$ for conservative treatment, $85.1 \%$ for microdisectomy, and $69.9 \%$ for percutaneous discectomy. ${ }^{3}$ The efficacy of percutaneous discectomy in athletes was not consistently reported in terms of their ability to return to play. ${ }^{5-7}$ A recent study demonstrated that $75 \%$ of patients who underwent conventional open discectomy returned to play again in the National Basketball Association (NBA) league, compared with $88 \%$ in control subjects who did not undergo the surgery. ${ }^{8}$ Although the inclusion and exclusion criteria of the study subjects were not identical among studies reviewed, the outcomes of conservative treatment, microdiscectomy, or conventional open discectomy in athletes with lumbar disc herniation appeared to be satisfactory in terms of their ability to return the injured athletes to play., ${ }^{3,8}$ No available studies were found for percutaneous laser discectomy or MED.

Previously, we reported that the short-term outcome of conservative treatment in 71 athletes with symptomatic lumbar disc herniation appeared to be satisfactory in terms of control of the symptoms and the ability of the athletes to return to play. ${ }^{9}$ The percentage of athletes who returned to play (the period until their return) was 78.9\% (4.7 months), and the severity of the symptoms prior to the start of treatment was the factor influencing the ability of the athletes to return to play. The purpose of this study was to extend an analysis for 100 athletes with symptomatic lumbar disc herniation in order to reconfirm the short-term outcome of conservative treatment in terms of the ability of the athletes to return to play and factors influencing their return to play after conservative treatment.

\section{Subjects and methods Subjects}

A total of 100 consecutive athletes who consulted our sports medicine clinic during the 16-year period between September 1993 and October 2009 because of severe low back pain and/or leg pain/numbness caused by lumbar disc herniation were the subjects of this study. After a questionnaire was administered and a physical examination was performed, six radiographs of the lumbar spine in the anteroposterior, right and left oblique, and lateral (neutral, flexion, and extension positions) views and images from magnetic resonance imaging (MRI) of the lumbar spine were obtained for all the athletes. These examinations are accepted as the standard for the diagnosis and management of low back problems at sports medicine clinics in Japan. The presence of lumbar disc herniation was confirmed by MRI of the lumbar spine in all the athletes. We define disc herniation as herniation of material from the nucleus pulposus and annulus fibrosus that could potentially cause low back pain and/or radiating leg pain/numbness, including the protrusion, extrusion, and sequestration type of disc herniations. ${ }^{10}$

\section{Inclusion and exclusion criteria}

The inclusion criteria of the subjects into the study were the presence of lumbar disc herniation on MRI of the lumbar spine; class 3 or 4 sporting activities (sports level) according to the following categorization: ${ }^{11}$ class 1 (nonathletic: sporting activity only a few times every month), class 2 (low-recreational: sporting activity once or twice every week), class 3 (high-recreational: sporting activity three or more times every week and belonging to a high school sports team or sports society), and class 4 (competitive: competitive sporting activity and belonging to a professional, industrial, or college sports team); and severity level 3 or 4 of symptoms according to the following categorization: level 0 (no symptoms during or after sporting activity), level 1 (low back pain and/or leg pain/numbness after sporting activity), level 2 (mild low back pain and/or leg pain/numbness during sporting activity), level 3 (severe low back pain and/or leg pain/numbness during sporting activity, necessitating discontinuation of the sporting activity), and level 4 (severe low back pain and/or leg pain/ numbness, making sporting activity impossible).

The exclusion criteria for the subjects included the absence of lumbar disc herniation on MRI of the lumbar 
spine even though low back pain and/or leg pain/numbness were present, the presence of lumbar spondylolysis or spondylolisthesis on radiographs of the lumbar spine (which are frequently associated with low back pain in athletes), ${ }^{12-14}$ the presence of cauda equine syndrome, class 1 or 2 sporting activities (sports level) according to our categorization as described previously, ${ }^{11}$ and severity level 1 or 2 of symptoms according to our categorization as described previously.

\section{Assessment}

The following characteristics of each athlete were recorded: sex, age, height, body weight, body mass index, sporting activity engaging in, type of symptoms (low back pain and/or leg pain/numbness), and neurological deficits. The severity of the neurological deficit was recorded according to the following classification: none (no muscle weakness, corresponding to grade 5 on manual muscle testing [MMT] and no sensory disturbance), mild (muscle weakness corresponding to grade 4 on MMT and/or mild sensory disturbance), and severe (muscle weakness corresponding to grade 3 or less on MMT and/or severe sensory disturbance).

Additionally, the number, level in the lumbar spine (L1/2, $\mathrm{L} 2 / 3, \mathrm{~L} 3 / 4, \mathrm{~L} 4 / 5$, and L5/S1), location in the spinal canal (lateral [outside of spinal canal], posterolateral, and central), and type (protrusion, extrusion, and sequestration) of disc herniation, ${ }^{10}$ as determined on MRI of the lumbar spine, were recorded. Combined radiographic abnormalities, ie, spinal instability and disc space narrowing, were also examined on the six radiographs of the lumbar spine obtained, according to our criteria. ${ }^{12,13}$

The efficacy of conservative treatment of the athletes with symptomatic lumbar disc herniation was clarified, especially in terms of their ability to return to play. Successful return of the athletes to play was defined as the ability of the athletes to participate in their original sports activities at the same or nearly the same level of participation as before the onset of their symptoms. The decision about the return was made with the consensus of the patients (athletes), managers, and trainers. As to the conservative treatment with/without shortterm medication, the subjects were advised to discontinue the aggravating sporting activity until a subjective reduction of the symptoms by more than $80 \%$, followed by commencement of individual training according to the sporting activity. Physiotherapy and rehabilitation in an outpatient clinic may also have played an important role in the ability of the athletes to return to play. However, because many athletes had their own established rehabilitation programs and the activities varied from sport to sport, there was no unified rehabilitation program for all the athletes. We did not employ any interventional pain management strategy such as facet joint injection or epidural block to help with physical therapy and facilitate rapid return to play. The effect of the treatment was assessed based on the percentage of athletes who showed subjective improvement of low back pain, leg symptoms, and neurological deficit; the percentage of athletes who returned to play; and the time until the complete return of the athletes to play. The minimum follow-up duration of the patients after their return to play was 6 months. Because many athletes usually had a season off for a certain period during the 1-year study period, longer follow-up (more than 6 months) of the subjects after their return to play became difficult. The status of all the athletes with respect to their ability to engage in their respective sporting activities was reported to the examiners in person, by telephone, or by mail by the athletes themselves or their trainers.

\section{Statistical analysis}

Factors that could potentially influence the ability of the athletes to return to play were examined by multiple logistic regression analysis. Furthermore, the relationships between the time until return to play and various factors were examined by multiple regression analysis. In these regression analyses, the following factors were replaced by numbers: sex (male: 1, female: 2 ), abnormalities in the lumbar radiographs (spinal instability: 1, disc space narrowing: 2 , both: 3 , neither: 0 ), low back pain (present: 1, absent: 0), leg pain/numbness (present: 1, absent: 0), severity of neurological deficit (severe: 2 , mild: 1 , none: 0 ), level of disc herniation (L3/4: 1, L4/5: 2, L5/S1: 3), location of disc herniation (posterolateral: 1 , central: 2 , lateral: 3 ), and type of disc herniation (protrusion: 1, extrusion: 2, sequestration: 3 ). The significance level was set at $P<0.05$ for all the statistical analyses.

\section{Results}

\section{Characteristics of study subjects}

Table 1 shows the characteristics of the study subjects. The mean age of the subjects was 23 years (range 15-46 years). The mean body mass index was $23.0 \mathrm{~kg} / \mathrm{m}^{2}$. Seventy-four athletes were engaging in class 3 sporting activities (sports level) and 26 were engaging in class 4 . Sixty-one athletes had level 3 severity of symptoms and 39 had level 4 .

With regard to the distribution of the sporting activities among the athletes, the most common was rowing $(\mathrm{n}=14)$, followed in frequency by baseball $(\mathrm{n}=11)$, rugby $(\mathrm{n}=10)$, basketball $(n=8)$, tennis $(n=7)$, dancing $(n=6)$, volleyball $(n=5)$, and hockey $(n=4)$. 
Table I Characteristics of study subjects

\begin{tabular}{lll}
\hline & $\begin{array}{l}\text { Mean } \pm \text { standard } \\
\text { deviation }\end{array}$ & Range \\
\hline Number of subjects & 100 & \\
Male/female & $72 / 28$ & \\
Age (years) & $23 \pm 7$ & $15-46$ \\
Height $(\mathrm{m})$ & $1.72 \pm 0.08$ & $1.52-1.94$ \\
Body weight $(\mathrm{kg})$ & $69 \pm \mathrm{I} 5$ & $44-146$ \\
Body mass index $\left(\mathrm{kg} / \mathrm{m}^{2}\right)$ & $23.0 \pm 3.7$ & $17.1-38.8$ \\
Class (sports level: $3 / 4)$ & $74 / 26$ & \\
Severity level of symptoms $(3 / 4)$ & $61 / 39$ & \\
\hline
\end{tabular}

\section{Characteristics of disc herniation and lumbar spine radiograph}

Table 2 shows the characteristics of the lumbar disc herniation in the study subjects. Eighty-five athletes suffered from single disc herniation and 15 athletes suffered from multiple disc herniations. The most common level of lumbar disc herniation was L4/5, followed in frequency by L5/S1 and L3/4. With regard to the location of lumbar disc herniation, 60 discs had posterolateral herniation and 56 had central herniation. With regard to the type of lumbar disc herniation, 60 disc herniations were extrusion types and 53 were protrusion types. Only three disc herniations were sequestration types. Spinal instability was encountered in 19 athletes and disc space narrowing was encountered in 15 athletes. Both spinal instability and disc space narrowing were encountered in nine athletes.

Table 2 Characteristics of lumbar disc herniation

\begin{tabular}{ll}
\hline & Number of subjects \\
\hline Disc herniation on magnetic resonance imaging \\
Level \\
L3/4 & 3 \\
L4/5 & 44 \\
L5/SI & 38 \\
L3/4 + L4/5 & 2 \\
L4/5 + L5/SI & 12 \\
L3/4 + L3/4 + L5/SI & 1 \\
Location & \\
Central & 56 \\
Posterolateral & 60 \\
Lateral & 0 \\
Type & \\
Protrusion & 53 \\
Extrusion & 60 \\
Sequestration & 3 \\
Radiographic abnormalities & \\
Spinal instability & 19 \\
Disc space narrowing & 15 \\
Both & 9 \\
None & 57 \\
\hline
\end{tabular}

Table 3 shows the characteristics of the disc herniationrelated symptoms in the subjects. The mean (standard error) duration of symptoms was 4.26 (5.44) weeks (range 0.14-24.0 weeks). Fifty-four athletes suffered from both low back pain and leg pain/numbness. Although 34 athletes had no neurological deficit, 64 athletes had mild neurological deficit. Numbness was not always associated with sensory disturbance. Patients without nerve root compression suffered from leg symptoms. In particular, two athletes with severe neurological deficit had muscle weakness corresponding to grade 3 on MMT. Because of their refusal of surgical treatment, they were treated conservatively.

\section{Outcome of conservative treatment}

Twenty-one patients $(21.0 \%)$ were unable to return to play because of the absence of any improvement in the low back pain, leg symptoms, and/or neurological deficit. However, the remaining 79 patients (79.0\%) successfully returned to play. The percentages of athletes who showed subjective improvement of the low back pain, leg symptoms, and neurological deficit were $62.8 \%, 74.0 \%$, and $68.6 \%$, respectively, suggesting that the leg symptoms responded better to conservative treatment than did the low back pain or neurological deficit. The subjects returned to play at an average of 4.8 months (range 1-12 months) after the start of the treatment and were able to sustain the activities for at least 6 months. The shortterm outcome of conservative treatment was similar in the athletes engaging in class 3 or 4 sporting activities (sports level), and the rate of return to play and the time until the return to play did not differ significantly between the athletes engaging in class 3 or 4 sporting activities (sports level).

\section{Factors influencing return to play after conservative treatment}

Multiple logistic regression analysis, including all the subjects (100 athletes) with single or multiple disc herniations, showed that the only factor that significantly influenced the return of

Table 3 Characteristics of symptoms

\begin{tabular}{ll}
\hline & Number of subjects \\
\hline Symptoms & \\
Low back pain & 29 \\
Leg pain/numbness & 17 \\
Both & 54 \\
Neurological deficit & \\
Severe & 2 \\
Mild & 64 \\
None & 34 \\
\hline
\end{tabular}


the athletes to play was the severity of the symptoms prior to the commencement of the conservative treatment (severity level) (Table 4). A similar result was obtained when the subjects included in the analysis were limited to 85 athletes with only a single disc herniation (Table 5). Because of the small number of the subjects engaging in class 4 sporting activities (sports level), multiple logistic regression analysis was not possible by the class of sporting activity.

The results of multiple regression analysis revealed no significant relationship between the time until return and various factors in the athletes who could return to play.

\section{Discussion}

The present study reconfirmed the short-term outcome of conservative treatment in athletes with symptomatic lumbar disc herniation in terms of the ability of the athletes to return to play and factors influencing their return to play after conservative treatment. Of 100 athletes with symptomatic lumbar disc herniation, $79.0 \%$ returned to play at an average of 4.8 months (range 1-12 months) after the start of treatment and were able to sustain the activities for at least 6 months. The severity of the symptoms prior to the start of treatment was the only factor influencing the ability of the athletes to return to play.

In nonathletes with lumbar disc herniation, the earlier return to function and pain relief with surgery (standard open discectomy) than with nonoperative treatment has been shown on the SPORT (Spine Patient Outcomes Research Trial). ${ }^{15}$ Weinstein et $\mathrm{al}^{16}$ reported that patients who underwent standard open discectomy for a lumbar disc herniation achieved greater improvement than did nonoperatively treated patients in all primary and secondary outcomes, but that the percentage

Table 4 Logistic regression analysis in all subjects $(\mathrm{n}=100)^{\mathrm{a}}$

\begin{tabular}{lll}
\hline Independent variables & $\chi^{2}$ & P value \\
\hline Age & 0.175 & NS \\
Sex & 0.350 & NS \\
Height & 0.092 & NS \\
Body weight & 1.187 & NS \\
Body mass index & 1.198 & NS \\
Class (sports level) & 0.119 & NS \\
Severity level of symptoms & 9.347 & $<0.01$ \\
Presence of low back pain & 0.001 & NS \\
Presence of leg pain/numbness & 0.010 & NS \\
Severity of neurological deficit & 3.099 & NS \\
Number of disc-herniated lesion & 0.060 & NS \\
Presence of spinal instability/disc & 0.388 & NS \\
space narrowing & & \\
\hline
\end{tabular}

Notes: a Factors that could affect return to sporting activities were examined by multiple logistic regression analysis. A dependent variable was return/nonreturn to play. Abbreviation: NS, not significant.
Table $\mathbf{5}$ Logistic regression analysis in subjects with only a single lesion $(\mathrm{n}=85)^{\mathrm{a}}$

\begin{tabular}{lll}
\hline Independent variables & $\chi^{2}$ & P value \\
\hline Age & 0.862 & NS \\
Sex & 0.604 & NS \\
Height & 0.427 & NS \\
Body weight & 0.698 & NS \\
Body mass index & 0.672 & NS \\
Class (sports level) & 0.221 & NS \\
Severity level of symptoms & 7.863 & $<0.01$ \\
Presence of low back pain & 1.397 & NS \\
Presence of leg pain/numbness & 0.483 & NS \\
Severity of neurological deficit & & NS \\
Characteristics of disc herniation & & \\
$\quad$ Level (L3/4, L4/5, L5/SI) & $1.869 \mathrm{e}^{-5}$ & $\mathrm{NS}$ \\
$\quad$ Location (posterolateral/central) & 0.867 & $\mathrm{NS}$ \\
$\quad$ Type (protrusion/extrusion/sequestration) & 0.652 & $\mathrm{NS}$ \\
Presence of spinal instability/disc & 0.007 & $\mathrm{NS}$ \\
space narrowing & &
\end{tabular}

Notes: a Factors that could affect return to sporting activities were examined by multiple logistic regression analysis. A dependent variable was return/nonreturn to play. Abbreviation: NS, not significant.

working was similar between the surgical and nonoperative groups. Peul et $\mathrm{al}^{17}$ reported that the rates of pain relief and perceived recovery were faster for those assigned to early surgery, but that the 1-year outcomes were similar for patients assigned to early surgery (microdiscectomy) and those assigned to conservative treatment. Thus, decompression of the nerve root by preserving muscle function and strength of the lower back might produce rapid improvement of symptoms induced by disc herniation. However, the long-term outcomes may be comparable between conservative and surgical treatments.

In athletes with lumbar disc herniation, a review of the literature revealed that the period until the return of athletes to play (the percentages of athletes who returned to play) was 4.7 months $(78.9 \%)$ for conservative treatment and 5.2-5.8 months ( $85.1 \%$ ) for microdisectomy, ${ }^{3}$ suggesting that the outcomes of conservative treatment or microdiscectomy in athletes with lumbar disc herniation appeared to be satisfactory in terms of their ability to return to play. ${ }^{3}$ However, an early return to play may, in general, be similarly difficult with conservative treatment or microdisectomy. Conversely, a retrospective cohort study by $\mathrm{Hsu}^{18}$ showed that $78 \%$ of National Football League (NFL) athletes returned to play at competitive levels after discectomy, because of the rigorous rehabilitation, and that players treated surgically played in more games post-treatment than did those treated nonoperatively. Thus, the outcome of conservative and surgical treatment is likely to be controversial regarding return to play. Strictly conducted randomized controlled trials (level 1) with 
an absolute definition of the return to play in elite athletes may be needed to establish the optimal strategy (conservative or surgical treatment) for the management of lumbar disc herniation associated with sports activities.

It is likely that less invasive surgical intervention involving the paravertebral muscle may have advantages in athletes to maintain muscle function, strengthen the lower back, and change some of the thinking about postoperative restrictions. ${ }^{1}$ Thus, alternative treatment methods, ie, conservative treatment or minimally invasive surgeries, are available for athletes. An approach to the management of symptomatic lumbar disc herniation, MED, was introduced in 1997. This operation utilizes a tubular retractor system and a microendoscope for visualization rather than the operating microscope. Recent literature suggests that MED may be as effective as the traditional lumbar microdiscectomy in relieving radiculopathy. ${ }^{19}$ It is important to study the efficacy of MED for lumbar disc herniation in athletes. When surgery is required, minimizing tissue dissection and strict adherence to an aggressive rehabilitation regimen may expedite an athlete's return to play. ${ }^{2}$ However, Watters and $\mathrm{McGirt}^{20}$ indicated that conservative discectomy resulted in a quicker return to work in nonathletes but an increased incidence of recurrent disc herniation. The intradiscal pressure was reported to be about 10 times lower in patients after discectomy than in individuals who had not been operated on. ${ }^{21}$ High recurrence rates and persisting postoperative low back pain in patients require serious attention. ${ }^{22}$

After surgical treatment, a number of factors go toward the decision to return to play. First, motivation to return is definitely the most important factor in athletes. Elite athletes are more likely to return to play than are nonelite athletes. A study by Watkins et $\mathrm{a}^{23}$ dealing with professional and Olympic athletes showed the satisfactory outcomes of microdiscectomy in terms of return to play, because elite athletes in general were highly motivated to return to play. Second, athletes who had single-level microdiscectomy were more likely to return to their original levels of sports activities than were those who had two-level microdiscectomies. ${ }^{24}$ Other factors included age, sex, quality of surgery performed, state of health, low back pain, sciatica, fatigue of the low back, muscle weakness of the leg, rehabilitation program, lack of time, loss of competitiveness due to long absence, loss of enthusiasm, loss of regular position, premature retirement from sports, temporal factors (season on/off) in seasonal sports, and coach's or manager's decision. . $^{5-23-25}$

In the present study, however, the severity of the symptoms was shown to be the factor significantly influencing the ability of the athletes to return to play after conservative treatment.
The short-term outcome did not significantly differ between the athletes engaging in class 3 or 4 sporting activities (sports level), probably because the baseline severity of the symptoms was similar in the two groups. A survey for athletes who did not return to play in the present study suggested that loss of motivation was the critical factor in discontinuing sporting activity among athletes.

Quantitative assessment of pain and quality of life using tools such as the visual analog scale, Roland-Morris Disability Questionnaire, EuroQoL 5 Dimensions, and 36-item Short Form, may be important in the management of athletes with lumbar spine injuries. In the present practice-based observational study, however, we did not use these tools. Further studies are needed to clarify the quantitative outcomes of conservative treatment in athletes with symptomatic lumbar disc herniation.

\section{Conclusion}

The present study confirmed the satisfactory short-term outcome of conservative treatment in athletes with symptomatic lumbar disc herniation regarding return to play. It was revealed that subjective symptoms prior to the start of treatment appeared to be a key factor in return to play after conservative treatment.

\section{Disclosure}

The authors report no funding sources of conflict of interest in this work.

\section{References}

1. Burnett MG, Sonntaq VK. Return to contact sports after spinal surgery. Neurosurg Focus. 2006;21:E5.

2. Dunn IF, Proctor MR, Day AL. Lumbar spine injuries in athletes. Neurosurg Focus. 2006;21:E4.

3. Iwamoto J, Sato Y, Takeda T, et al. The return to sports activity after conservative or surgical treatment in athletes with lumbar disc herniation. Am J Phys Med Rehabil. 2010 (online publication).

4. Postacchini F. Results of surgery compared with conservative management for lumbar disc herniation. Spine. 1996;11:1383-1387.

5. Matsunaga S, Sakou T, Taketomi E, et al. Comparison of operative results of lumbar dics herniation in manual laborers and athletes. Spine. 1993;15:2222-2226.

6. Sakou T, Masuda A, Yone K, et al. Percutaneous discectomy in athletes. Spine. 1993;18:2218-2221.

7. Mochida J, Nishimura K, Okuma M, et al. Percutaneous nucleotomy in elite athletes. J Spinal Disord. 2001;14:159-164.

8. Anakwenze OA, Namdari S, Auerbach JD, et al. Athletic performance outcomes following lumbar discectomy in professional basketball players. Spine. 2010;35:825-828.

9. Iwamoto J, Takeda T, Sato Y, et al. Short-term outcome of conservative treatment in athletes with symptomatic lumbar disc herniation. Am J Phys Med Rehabil. 2006;85:667-674.

10. Macnab I, McCulloch J. Spondylogenic backache. In: Macnab I, McCulloch J, editors. Backache. 2nd ed. Baltimore: Williams \& Wilkins; 1990;120-147. 
11. Iwamoto J, Takeda T. Stress fractures in athletes: review of 196 cases. J Orthop Sci. 2003;8:273-278.

12. Iwamoto J, Abe H, Tsukimura Y, et al. Relationship between radiographic abnormalities of lumbar spine and incidence of low back pain in high school and college American football players: a prospective study. Am J Sports Med. 2004;32:781-786.

13. Iwamoto J, Abe H, Tsukimura Y, et al. Relationship between radiographic abnormalities of lumbar spine and incidence of low back pain in high school rugby players: a prospective study. Scand J Med Sci Sports. 2005;15:163-168.

14. Iwamoto J, Sato Y, Takeda T, et al. Return to sports activity by athletes after treatment of spondylolysis. World J Osthop. 2010 (online publication).

15. Atlas SJ, Tosteson TD, Blood EA, et al. The impact of workers' compensation on outcomes of surgical and nonoperative therapy for patients with a lumbar disc herniation: SPORT. Spine. 2010;35:89-97.

16. Weinstein JN, Lurie JD, Tosteson TD, et al. Surgical versus nonoperative treatment for lumbar disc herniation: four-year results for the Spine Patient Outcomes Research Trial (SPORT). Spine. 2008;33: 2789-2800.

17. Peul WC, van Houwelingen HC, van den Hout WB, et al. Surgery versus prolonged conservative treatment for sciatica. $N$ Engl J Med 2007;356:2245-2256.
18. Hsu WK. Performance-based outcomes following lumbar discectomy in professional athletes in the National Football League. Spine. 2010;35: 1247-1251.

19. Riesenburger RI, David CA. Lumbar microdiscectomy and microendoscopic discectomy. Minim Invasive Ther Allied Technol. 2006;15: 267-270.

20. Watters WC 3rd, McGirt MJ. An evidence-based review of the literature on the consequences of conservative versus aggressive discectomy for the treatment of primary disc herniation with radiculopathy. Spine $J$. 2009;9:240-257.

21. Shahadi F, Luecke M, Preuss M, et al. Measurement of intradiscal pressure after lumbar discectomy. Zentralbl Neurochir. 2008;69:87-89.

22. Bron JL, Helder MN, Meisel HJ, et al. Repair, regenerative and supportive therapies of the annulus fibrosus: achievements and challenges. Eur Spine J. 2009;18:301-313.

23. Watkins RG 4th, Williams LA, Watkins RG 3rd. Microscopic lumbar discectomy results for 60 cases in professional and Olympic athletes. Spine J. 2003;3:100-105.

24. Wang JC, Shapiro MS, Hatch JD, et al. The outcome of lumbar discectomy in elite athletes. Spine. 1999;24:570-573.

25. Weber J, Schönfeld C, Spring A. Sports after surgical treatment of a herniated lumbar disc: a prospective observational study [in German]. Z Orthop Unfall. 2009;147:588-592.
Open Access Journal of Sports Medicine

\section{Publish your work in this journal}

Open Access Journal of Sports Medicine is an international, peer-reviewed, open access journal publishing original research, reports, reviews and commentaries on all areas of sports medicine. The manuscript management system is completely online and includes a very quick and fair peer-review system.

\section{Dovepress}

Visit http://www.dovepress.com/testimonials.php to read real quotes from published authors. 